\title{
Electrophysiological Characterization of The Cerebellum in the Arterially Perfused Hindbrain and Upper Body of The Rat
}

\author{
Nadia L. Cerminara $\cdot$ John A. Rawson • Richard Apps
}

Published online: 22 December 2009

(C) The Author(s) 2009. This article is published with open access at Springerlink.com

\begin{abstract}
In the present study, a non-pulsatile arterially perfused hindbrain and upper body rat preparation is described which is an extension of the brainstem preparation reported by Potts et al., (Brain Res Bull 53(1):59-67), 1. The modified in situ preparation allows study of cerebellar function whilst preserving the integrity of many of its interconnections with the brainstem, upper spinal cord and the peripheral nervous system of the head and forelimbs. Evoked mossy fibre, climbing fibre and parallel fibre field potentials and EMG activity elicited in forelimb biceps muscle by interpositus stimulation provided evidence that both cerebellar inputs and outputs remain operational in this preparation. Similarly, the spontaneous and evoked single unit activity of Purkinje cells, putative Golgi cells, molecular interneurones and cerebellar nuclear neurones was similar to activity patterns reported in vivo. The advantages of the preparation include the ability to record, without the complications of anaesthesia, stabile single unit activity for extended periods ( $3 \mathrm{~h}$ or more), from regions of the rat cerebellum that are difficult to access in vivo. The preparation should therefore be a useful adjunct to in vitro and in vivo studies of neural circuits underlying cerebellar contributions to movement control and motor learning.
\end{abstract}

N. L. Cerminara $(\bowtie) \cdot R$. Apps

Department of Physiology and Pharmacology,

School of Medical Sciences, University of Bristol,

University Walk,

Bristol BS8 1TD, UK

e-mail: n.cerminara@bristol.ac.uk

\section{J. A. Rawson}

Department of Physiology, Monash University,

Clayton, Australia
Keywords Purkinje cell · Climbing fibre · Mossy fibre · Parallel fibre $\cdot$ Nucleus interpositus

\section{Introduction}

The cerebellum is an ideal brain structure to study neuronal network mechanisms as its connections are well characterised. It is the largest sensorimotor structure within the CNS and is intimately involved in the regulation of smooth and accurate movements. It also contributes to our ability to improve movements through experience and practice, and an increasing body of evidence suggests that it may also be involved in non-motor processes such as sensory, autonomic and cognitive functions (see $[2,3]$ for details). In view of the remarkable structural uniformity of its intrinsic circuitry, it is likely that the cerebellum performs a similar computation on the information it receives irrespective of the specific function in question [4]. Diversity of function between different cerebellar regions is thought to arise primarily from differences in regional input and output connectivity (e.g. [5]).

In terms of inputs, many in vivo electrophysiological studies in anaesthetised, decerebrate and awake animals have shown that sensory information arising from peripheral receptors in muscle, skin and joints can be highly effective at altering on-going neural activity in the cerebellum (e.g [6-9]). Related anatomical studies have also provided important details regarding the 'wiring' of brain circuits linking the cerebellum to other major structures within the CNS; both in terms of cerebellar inputs, notably the inferior olive [10] and the pontine nuclei, [11]; and also in terms of cerebellar outputs e.g. the red nucleus [12]. 
By comparison, the ability to manipulate the ionic environment and high mechanical stability of in vitro brain slice preparations and tissue-cultured neurones has provided important details of the cellular mechanisms and synaptic events that underlie cerebellar function (e.g. [13-16]). However, an important limitation of such preparations is that they usually lack neuronal connections with other parts of the CNS, and invariably deprive the cerebellum of its links with the rest of the body. Indeed, normal cerebellar function is dependent on maintaining its afferent and efferent connections with other brain structures (especially the inferior olive, e.g. [17-19]).

We have therefore assessed the utility of a non-pulsatile, perfused hindbrain and upper body preparation (PHBP) to study the neuronal mechanisms of the intact cerebellum in situ. Previously, a similar preparation (but lacking a cerebellum) has been used to examine brainstem mechanisms that underlie cardio-respiratory control $[1,20]$. Other cerebellar preparations have succeeded in providing good recording stability whilst maintaining major links between the cerebellum and brainstem [21-27], but the in situ preparation described here also maintains interconnectivity with the peripheral nervous system and muscles of the upper body, thereby allowing a study of cerebellar activity in the context of intact neural systems.

\section{Methods}

\section{Surgical Procedures}

Figure 1 shows a schematic diagram of the experimental setup. All surgical and experimental procedures were approved and performed in accordance with local animal welfare

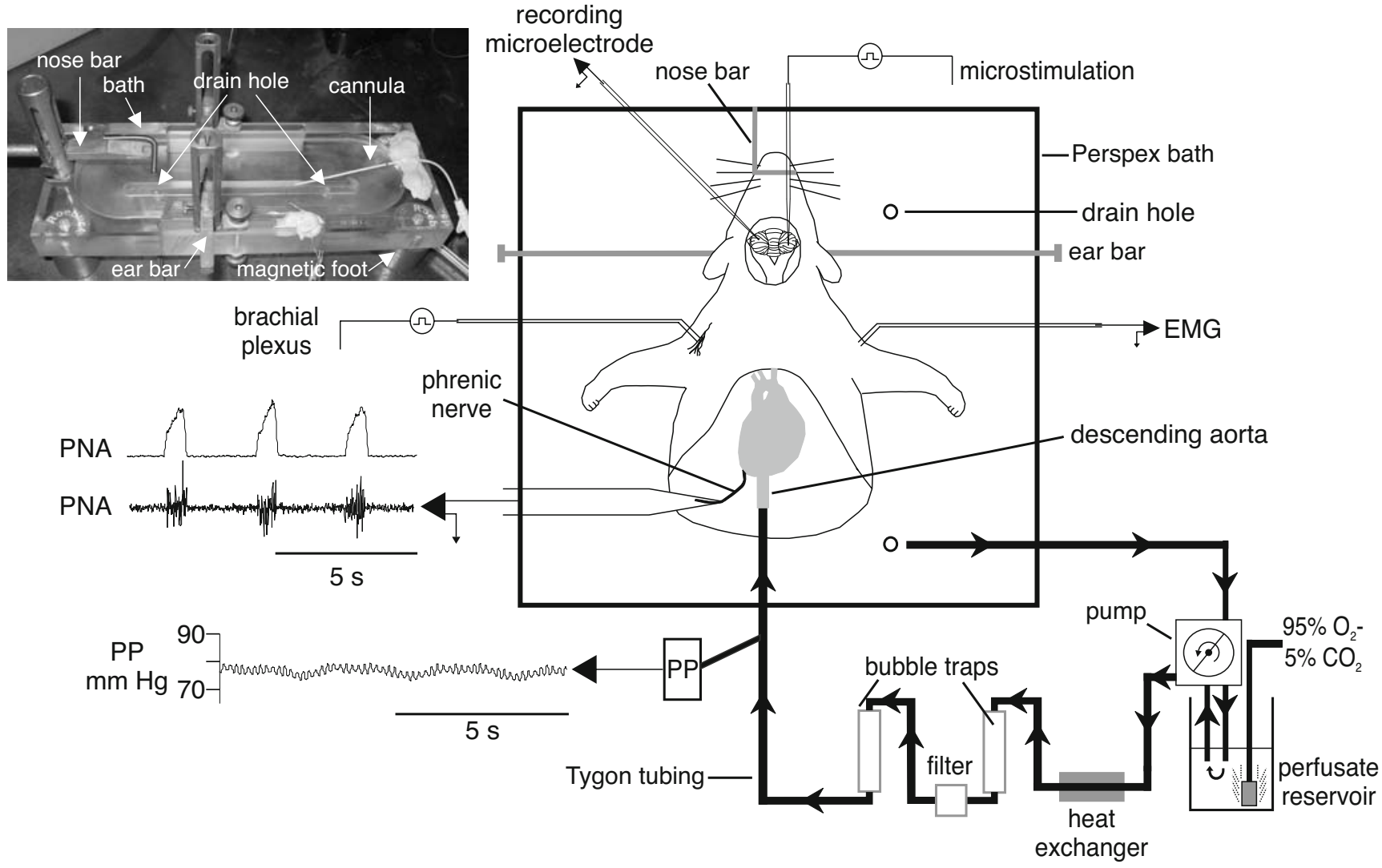

Fig. 1. Schematic diagram of the perfused hindbrain and upper body preparation of the rat. The chamber is constructed from Perspex and held in place on a steel table with magnetic feet. The rat is decerebrated and perfused with a modified Ringer's solution gassed with $95 \% \mathrm{O}_{2} / 5 \% \mathrm{CO}_{2}$ mixture via a double lumen cannula inserted into the descending aorta. Perfusion pressure $(P P)$ is monitored via the second lumen of the cannula. The rat is held in place with ear and nose bars. A peristaltic pump is used to circulate the perfusate. Two drain holes in the bottom of the chamber return the perfusate efflux to the perfusate reservoir for reperfusion. Tygon tubing is used to connect the circuitry. Arrows indicate the direction of perfusate flow. The flow rate of the perfusate was altered until phrenic nerve activity (PNA) monitored via a suction electrode displayed a eupneic (ramp-like) pattern. PNA was integrated to show more clearly the rhythmic activity consistent with eupnoea. Extra- and intracellular recordings were made from individual cerebellar neurones. Electrical stimulation of the brachial plexus or cerebellar cortex was used to evoke cerebellar field potentials. Forelimb muscle contraction evoked by microstimulation of nucleus interpositus was monitored by EMG recordings from the ipsilateral biceps brachii muscle. See "Methods" for further details 
guidelines and the UK Animal (Scientific Procedures) Act 1986. Ten minutes prior to the commencement of the experiment, the animal received a $0.1-0.2 \mathrm{ml}$ intraperitoneal injection of heparin $(1,000 \mathrm{mg} / \mathrm{ml})$ to prevent the coagulation of blood during preparation. According to Paton's [20] original description in the mouse, 25 Wistar rats of either sex weighing between 85-120 g (4-6 weeks of age) were deeply anaesthetised with halothane and bisected below the diaphragm. The upper half of the body was immediately transferred to ice-cold modified Ringer's solution bubbled with carbogen. The rostral brain was exposed and the preparation was decerebrated rostral to the superior colliculus by aspiration or with a blunt spatula. With the exception of the forepaws and face, the preparation was skinned to prevent fur from blocking the tubing as well as pathogens contaminating the perfusate and degrading the preparation. Within the thorax, the descending aorta was dissected free, the phrenic nerve cut at the level of the diaphragm and the lungs removed. The preparation was then transferred to a custom made Perspex recording chamber held in place on a steel table by magnetic feet (Fig. 1 inset). The descending aorta was rapidly cannulated with a double lumen cannula (DLR-4, Braintree Scientific, MA, USA) for retrograde perfusion of modified Ringer's solution $(125 \mathrm{mM} \mathrm{NaCl}$, $24 \mathrm{mM} \mathrm{NaHCO}, 10 \mathrm{mM}$ dextrose, $5 \mathrm{mM} \mathrm{KCl}, 2.5 \mathrm{mM}$ $\mathrm{CaCl}_{2}, 1.25 \mathrm{mM} \mathrm{MgSO}, 1.25 \mathrm{mM} \mathrm{KH} \mathrm{KO}_{4}, \mathrm{pH} 7.4$ ) containing $1.25 \%$ of the oncotic agent Ficoll 70 or $1 \%$ Polyethylene glycol. All chemicals were purchased from Sigma-Aldrich. The second lumen of the cannula was used to monitor perfusion pressure via a pressure transducer. The cannula was held in place by securely tying a length of suture around the aorta. The perfusate was gassed continuously with $95 \% \mathrm{O}_{2} / 5 \% \mathrm{CO}_{2}$ gas mixture and pumped from a reservoir flask at a constant flow rate of 25-44 ml/min using a peristaltic roller pump (Watson-Marlow, Falmouth, $520 \mathrm{~S}$, UK). The perfusate passed through a heat exchanger where it was warmed to $37^{\circ} \mathrm{C}$ before passing through (1) a bubbletrap which served to remove gas bubbles and dampen pulsations from the roller pump; (2) a polypropylene mesh filter ( $25 \mu \mathrm{m}$, Millipore) to prevent cell debris from entering the preparation; and (3) a second bubble-trap before passing into the preparation via the cannula. The perfusate efflux was recycled back to the perfusate reservoir via two drainage holes in the bottom of the chamber in order to prevent the wash-out of nutrients. The total volume of the perfusate circulating through the system was $200 \mathrm{ml}$. Tygon tubing (1/16"ID 3/16/4"OD; Cole Palmer) was used to connect the circuitry, and care was taken to minimise the dead space. The set-up was enclosed in a Faraday cage with the exception of the roller pump which was positioned just outside the cage.

As soon as the aorta was cannulated, the pump flow rate (and thereby perfusion pressure) was gradually increased until respiratory activity resumed, typically when the mean perfusion pressure reached $40 \mathrm{mmHg}$. The pump flow rate was adjusted until phrenic nerve activity displayed a phasic, 'ramp-like pattern' indicating eupnoea, which was used to gauge adequate oxygenation of the brainstem (Fig. 1). Perfusion pressure was maintained at $70-100 \mathrm{mmHg}$ for the flow rates used in this study. In all experiments (with the exception of those involving EMG recordings), the paralysing agent vecuronium bromide $(0.04 \mu \mathrm{g} / \mathrm{ml}$, Norcuron, Organon Teknica, Cambridge, UK), was added to the perfusate to block neuromuscular transmission. In two experiments, harmaline was added to the perfusate $(5 \mu \mathrm{g} / \mathrm{ml}$, SigmaAldrich) to assess the effects of a pharmacological challenge on the olivo-cerebellar system.

Once the perfusion pressure was stable, the animal was secured in place by atraumatic ear bars and a nose clamp attached to the Perspex bath. By removing the intraparietal and occipital bone, the entire surface of the cerebellum was exposed (including regions not normally accessible in vivo, such as the anterior lobe and the most lateral parts of the hemispheres). The dura was carefully removed. The circulating perfusate prevented the surface of the cerebellum from drying out. A 30 gauge T-type thermocouple wire (W-TW-30, Physitemp Instruments, Clifton, NJ, USA) was inserted just rostral to the cerebellum to monitor brain temperature via a microprobe thermometer (BAT-12, Physitemp Instruments, Clifton, NJ, USA) and maintained at approximately $32-34^{\circ} \mathrm{C}$.

\section{Stimulation Methods}

In individual experiments one or more of the following stimulation procedures was carried out: (1) stimulation of cerebellar cortical parallel fibres was achieved with a glassinsulated tungsten microelectrode insulated up to the tip (tip diameter $15-25 \mu \mathrm{m}$ ) and positioned at or just below the surface of the cerebellar cortex and in line with the recording electrode placed at a distance $0.5-1.0 \mathrm{~mm}$ away in the long axis of the folium. Cathodal square pulses of $0.1 \mathrm{~ms}$ duration and up to $15 \mu \mathrm{A}$ in strength were delivered every 2 s. (2) To evoke climbing fibre responses in the $\mathrm{C} 1$ zone of the paramedian lobule [28] bipolar percutaneous needles were inserted into the ipsilateral brachial plexus. Square wave constant-voltage electrical stimulation of $0.1 \mathrm{~ms}$ duration was delivered every $2 \mathrm{~s}$ at intensities $<5 \mathrm{~V}$ which was sufficient to generate a small but visible twitch of the forelimb. (3) Stimulation of mossy fibres was achieved by dissecting free the facial nerve from the surrounding connective tissue and the exposed tips of Telfon-coated silver wires were wrapped around the nerve for electrical stimulation $(0.2 \mathrm{~ms}$ constant voltage square wave pulses, $<15 \mathrm{~V}$, or $0.1 \mathrm{~ms}$ constant current square wave pulses, $<2 \mathrm{~mA}$ delivered once every $2 \mathrm{~s}$ ). The prepared 
nerve was then embedded in fast-curing dental impression to prevent it drying out (Xantopren, Heraeus Kulzer, NY). (4) To stimulate nucleus interpositus, a concentric bipolar electrode was used. Cathodal constant current pulses $(0.2 \mathrm{~ms}, 100-200 \mu \mathrm{A})$ were delivered once every $2 \mathrm{~s}$. At some cerebellar nuclear sites, pulse trains $(0.1 \mathrm{~s}, 300 \mathrm{~Hz})$ were also employed. To verify the location of the stimulating electrode in nucleus interpositus, the cerebellum was removed at the end of the experiment (typically $4-5 \mathrm{~h}$ after the initial decerebration) and sunk in a solution of $10 \%$ formaldehyde and $20 \%$ sucrose. Sagittal sections were cut on a freezing microtome at a thickness of $100 \mu \mathrm{m}$. Sections were mounted serially onto slides, counterstained with cresyl violet, and dehydrated, cleared and coverslipped and scrutinised with a light microscope.

\section{Recording Parameters and Data Processing}

In every experiment the respiratory motor pattern was monitored by recording phrenic nerve activity via a glass suction electrode. Phrenic nerve signals were amplified and band-pass filtered $(0.08-3 \mathrm{kHz})$. In most experiments, extracellular recordings from single cerebellar neurones were made with high impedance glass-insulated tungsten microelectrodes (3-5 M $\Omega$ ). For intracellular recording glass micropipettes containing $3 \mathrm{M} \mathrm{KCl}$ or $3 \mathrm{MK}$-acetate were used (40-80 M $\Omega$ ). Signals were differentially amplified and band-pass filtered $(0.1-10 \mathrm{kHz})$. In additional experiments, field recordings from the cerebellar surface were made with low impedance glass-insulated tungsten microelectrodes $(\sim 50 \mathrm{k} \Omega)$. These signals were differentially amplified and band-pass filtered at $0.3-5 \mathrm{kHz}$. The ipsilateral forelimb response to interpositus stimulation was monitored by EMG recordings with a pair of fine needle electrodes inserted into the biceps brachii muscle. EMG activity was amplified and filtered $(0.1-5 \mathrm{kHz})$ through a differential amplifier. Perfusion pressure and electrophysiological recordings were digitised at 4 and $20 \mathrm{kHz}$ respectively via a data acquisition system (Micro1401 or 1401plus, Cambridge Electronic Design, UK) that was interfaced with a computer running customised Spike2 software (Cambridge Electronic Design) for off-line analysis. Single-unit spikes were discriminated using Spike2 template matching. Interspike interval (ISI) histograms and autocorrelograms were computed for each cerebellar neurone using a bin width of $1 \mathrm{~ms}$ and $2 \mathrm{~ms}$ respectively and a $180 \mathrm{~s}$ sampling interval. The coefficient of variation, $(\mathrm{CV}=$ standard deviation ISI/mean ISI) was used to describe the regularity of the resting discharges [29]. A high CV signifies a spike train with high ISI variability, whereas a low $\mathrm{CV}$ value indicates a more regular pattern of firing. All mean values given in "Results" are expressed as mean \pm standard error mean (SEM).

\section{Results}

\section{Evoked Field Potential Responses}

The threshold for evoking cortical responses by parallel fibre stimulation is well known to be highly sensitive to the viability of the cerebellum $[25,30]$. We therefore used local cortical electrical stimulation to evoke parallel fibre volleys in five preparations (see "Methods" for further details). As shown in Fig. 2a, electrical stimuli applied to the surface of the cerebellar cortex elicited a brief triphasic positivenegative-positive response, characteristic of compound action potentials propagating in a bundle of parallel fibres recorded in the molecular layer [30]. Threshold currents ranged between $3-5 \mu \mathrm{A}$. When the recording electrode was moved $300 \mu \mathrm{m}$ off line from the stimulating electrode, the triphasic response was no longer evident, consistent with earlier reports that the volley is restricted to a narrow 'beam' of parallel fibres $[31,32]$. Conduction velocities were determined from the peak of the initial positive wave. In the example illustrated in Fig. 2a, the conduction velocity was $0.36 \mathrm{~ms}^{-1}$. For all five experiments conduction velocities were on average $0.32 \pm 0.04 \mathrm{~ms}^{-1}$. These values are in good agreement with those reported previously for in vivo preparations for e.g. $0.33-0.5 \mathrm{~ms}^{-1}[30,33]$ but are faster than those reported in vitro for e.g. $0.2-0.3 \mathrm{~ms}^{-1}$ [34].

In three preparations, the response of individual Purkinje cells to parallel fibre stimuli was also observed and consisted of a single action potential (a simple spike) with an onset latency of $2.2 \pm 0.26 \mathrm{~ms}(n=3)$ (Fig. 2b). Such responses could be evoked with threshold currents below $5 \mu \mathrm{A}$, suggesting that parallel fibre excitatory synaptic input to Purkinje cells was operating normally in the PHBP [cf. 35].

To assess the integrity of mossy fibre inputs, in three experiments we recorded responses evoked by facial nerve stimulation in the molecular and granular layers of lobule IXa [cf. 36-38]. In the granular layer, stimulation of the ipsilateral facial nerve evoked an initial diphasic positivenegative wave (P1-N1, Fig. 2c, lower panel) which relates to the arrival of the mossy fibre volley [38]. A later negative wave (N2, Fig. 2c) has been ascribed to the synaptic activation of granule cells and Golgi cells [38] while the consequent activation of the parallel fibres by the granule cells results in a P2 wave with an average latency of $4.6 \mathrm{~ms} \pm 0.54(n=3)$. As in previous studies, an additional early positive response attributed to the brainstem was evident before the P1 wave, and did not reverse polarity between the molecular and granular layers [36, 37]. By contrast, and consistent with previous studies, the P2 wave was found to reverse polarity in the molecular layer to produce a negative-going deflection $(\mathrm{N} 3$, Fig. 2c, upper panel). 
Fig. 2. Evoked cerebellar cortical field potentials. a Field potential elicited by parallel fibre stimulation and recorded 'on beam' in the molecular layer of the cerebellar cortex. Depth of recording microelectrode from cortical surface $=100 \mu \mathrm{m}$. b Individual Purkinje cell response to parallel fibre stimulation. c Evoked field potentials in the molecular layer (top) and granular layer (bottom) in response to mossy

fibre-parallel fibre activation. Field potentials are defined in accordance with Eccles et al., 1967b. d Climbing fibre field potential evoked in the $\mathrm{C} 1$ zone of the paramedian lobule after electrical stimulation of the brachial plexus at $3 T(T=2.5 \mathrm{~V}$, where $T$ is defined as the stimulus which evokes a just detectable cerebellar response). e Graph shows the magnitude of the test response (expressed as a $\%$ of control) plotted as a function of different interstimulus intervals of the mossy fibre N3 wave in the experiment shown in c. f Same as e but for the climbing fibre field shown in $\mathbf{d}$. In $\mathbf{e}$ and $\mathbf{f}$, each value is an average of 14 trials $( \pm$ SEM). Records a-d are an average of ten consecutive trials. Stimulus artifact indicated by arrowheads
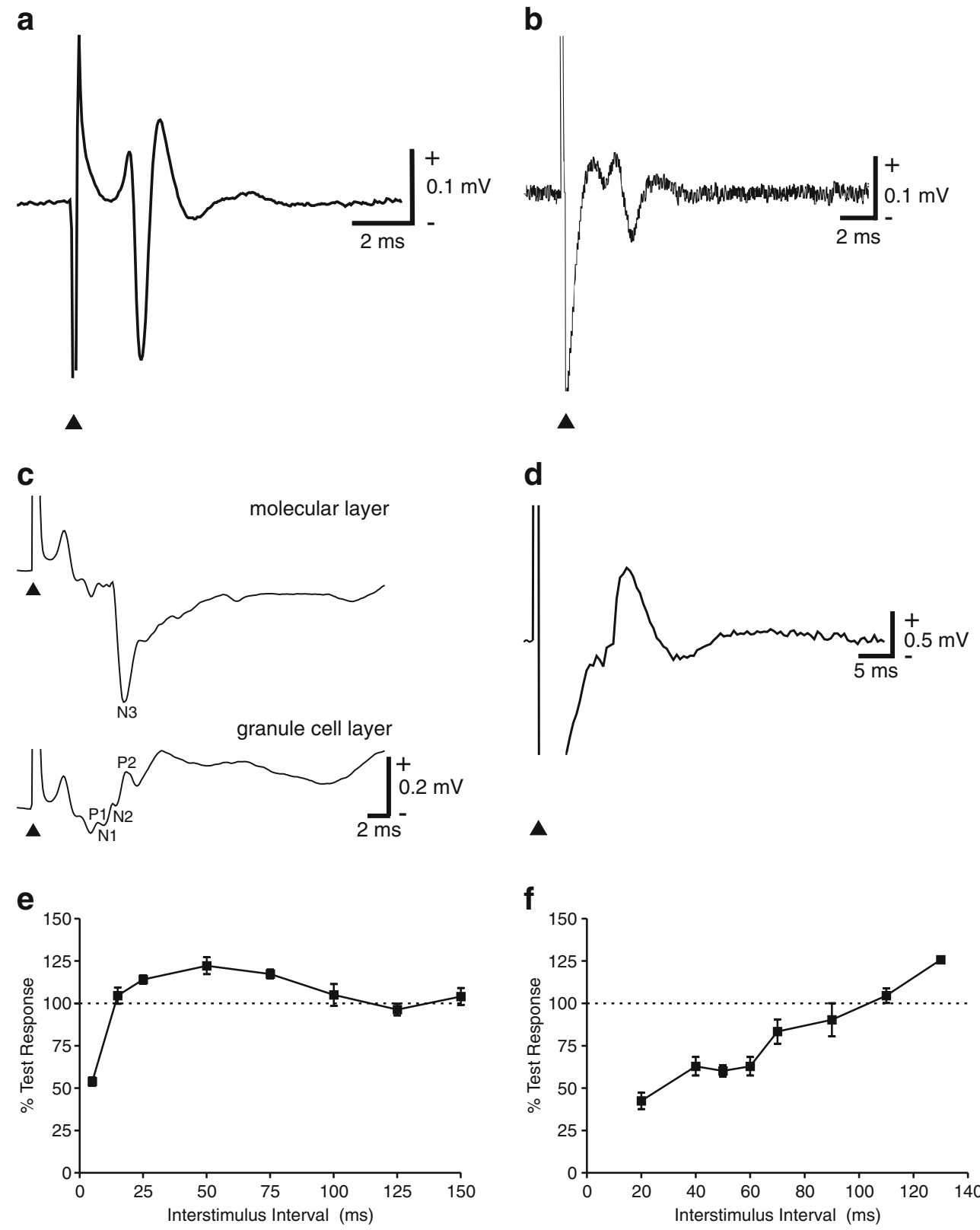

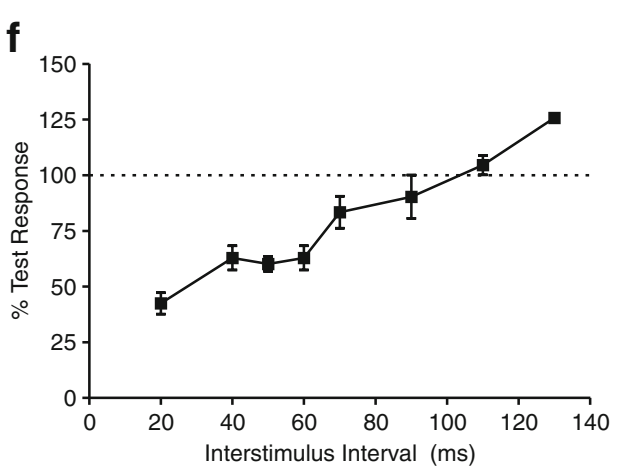

To assess the integrity of climbing fibre inputs to the cerebellum we electrically stimulated the ipsilateral brachial plexus, and recorded evoked field potentials (Fig. 2d) in the forelimb receiving area of the cerebellar cortex, located in the $\mathrm{C} 1$ zone of the paramedian lobule [28]. These responses were located in the medial part of the paramedian lobule and had an onset latency of $9.4 \pm$ $0.6 \mathrm{~ms}(n=3)$. The waveform, cortical location and onset latency of these field potentials were characteristic of climbing fibre responses evoked in the cerebellar cortical $\mathrm{C} 1$ zone as described previously in vivo in a number of species [e.g. cat, 39, rat, 28, 40, ferret, 41]. Moreover, when pairs of responses were evoked with supramaximal stimuli delivered at intervals between 20-150 ms (the paired pulse test), the second response displayed a reduction in amplitude (Fig. 2f). This is an additional feature of climbing fibre evoked field potentials [42, 43]. Consistent with climbing fibre responses, a rebound facilitation was also present at longer interstimulus intervals (Fig. 2f). Note also that the gradable nature of the evoked responses indicates that they were not unitary but represented the summed activity of a population of cerebellar neurones (Purkinje cells). As with previous studies in vivo [36], when shorter latency ( 3-5 ms) responses attributable to activation of mossy fibres were evoked by the peripheral stimulation, these were much less reduced in amplitude by the paired pulse test and were even increased in some instances (Fig. 2e). 
To assess the integrity of cerebellar output in the PHBP in two preparations we used microstimulation in nucleus interpositus and recorded evoked EMG activity in the ipsilateral forelimb. Electrical stimulation of nucleus interpositus either with single pulses or with trains of stimuli could readily evoke EMG activity in the ipsilateral forelimb muscle biceps brachii (latency 10-20 ms, Fig. 3a). As the stimulating electrode was advanced into the cerebellum the stimulus intensity required to evoke a detectable EMG response progressively decreased until a site was found that elicited EMG activity with a minimum threshold $(200-300 \mu \mathrm{A})$. Systematic study of threshold levels as a function of stimulus frequency was not carried out, nevertheless, it was noted that an increase in the frequency of the pulse train resulted in a decrease in the stimulus threshold as reported previously in vivo [44, 45]. Application of a neuromuscular blocker to the perfusate abolished the EMG responses, indicating that they were generated by neuromuscular synaptic transmission. Histological reconstruction of the stimulation site indicated that
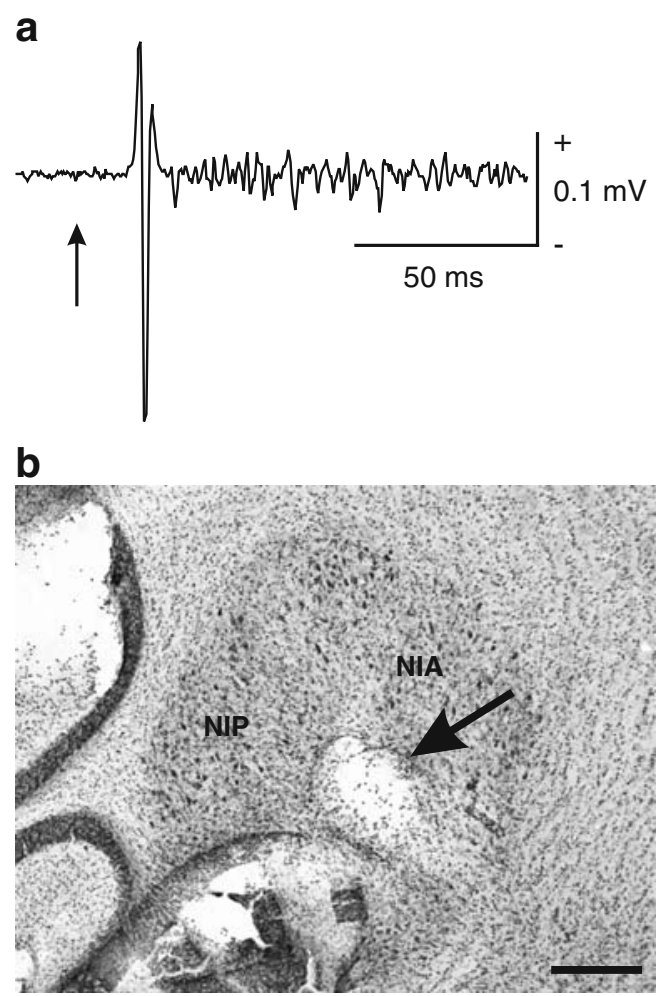

Fig. 3. EMG responses evoked by cerebellar nuclear microstimulation. a EMG response recorded in ipsilateral biceps brachii muscle evoked by single pulse stimulation of nucleus interpositus. Stimulus strength was $200 \mu \mathrm{A}$. Average of ten trials. Arrow indicates time of stimulus. b High-power photomicrograph of a cresyl violet-stained sagittal section of the cerebellum demonstrating the location of the stimulating electrode tip, indicated by an arrow, within NIA. NIA nucleaus interpositus anterior NIP nucleus interpositus posterior. Scale bar, $200 \mu \mathrm{m}$ in both experiments the electrode tip where minimum stimulation currents were used was located in nucleus interpositus anterior (Fig. 3b).

The latency, localization of optimal stimulation site, histological verification and the abolition of the response by a neuromuscular blocker provide strong evidence that the EMG activity was due to stimulation of cerebellar nucleofugal pathways, involving brainstem descending motor pathways $[44,46]$.

In summary, the responses evoked by mossy fibre, parallel fibre and climbing fibre activation were remarkably similar to those described previously in vivo [e.g. 30, 42, 47], suggesting that excitatory synaptic inputs to Purkinje cells are preserved in the PHBP. Similarly, the EMG responses evoked by cerebellar nuclear microstimulation suggest that at least part of the cerebellar output to the forelimbs is also preserved in this preparation.

\section{Activity Patterns of Individual Cerebellar Neurones}

To further assess cerebellar function in the PHBP we obtained extracellular recordings from single cerebellar neurones in 15 preparations. Electrode penetrations were made orthogonal to the cerebellar cortical surface and spontaneous spike trains were obtained from a total of 50 single units. These were obtained from a wide range of different lobules (including anterior parts of the cerebellum not directly accessible in vivo), and also from a range of medial-lateral positions. No systematic differences in response properties were observed in relation to anatomical location. The stability of the preparation meant that single units could be readily recorded for extended periods of time (when tested, for as long as $3.5 \mathrm{~h}$ ). All units were spontaneously active. Of the 50 units studied in detail, 25 were identified as Purkinje cells based on the presence of complex spikes in their spike trains (Fig. 4a). Three of the 25 Purkinje cells displayed only complex spikes. Complex spikes had low firing rates, occurring at mean frequencies that ranged in individual Purkinje cells between $0.10-5.15 \mathrm{~Hz}$ (Fig. 4 bi, Table 1, overall mean of $0.77 \pm 0.20 \mathrm{~Hz}, n=25$ cells). Complex spike firing patterns were highly irregular; as shown by their coefficient of variation (Table 1), and by their range of interspike intervals (Fig. 4 bii; the shortest interval was $7.84 \mathrm{~s}$ and the longest was $10.44 \mathrm{~s}$, Table 1). Complex spike autocorrelograms (Fig. 4 biii) revealed no obvious regularity or rhythmicity.

Simple spikes were usually biphasic positive-negative actions potentials with a duration of $>0.4 \mathrm{~ms}$ (Fig 4a). Simple spike firing patterns were also irregular as shown by interspike interval histograms which were positively skewed (Fig. 4 cii), and also by the coefficient of variation of their interspike intervals (range, $0.26-3.19 \mathrm{~ms}$; mean $=0.96 \mathrm{~ms} \pm 0.14, n=22$, 
Fig. 4. Purkinje cell single unit recordings. a Recording from a Purkinje cell showing spontaneous complex (dot) and simple spike activity. Lower panel shows ten superimposed complex spikes (left hand panel) and simple spikes (right hand panel). bi Population histogram of mean firing rates of complex spikes $(n=25)$. bii Complex spike interspike interval distribution. biii Autocorrelogram of complex spike spontaneous activity. ci Simple spike interspike interval distribution. cii Population histogram of mean firing rates of simple spikes $(n=22)$. ciii Autocorrelogram of simple spike spontaneous activity. d Sample trace of an intracellular Purkinje cell recording at the level of the proximal dendrites. $\mathrm{CV}$ coefficient of variation

a

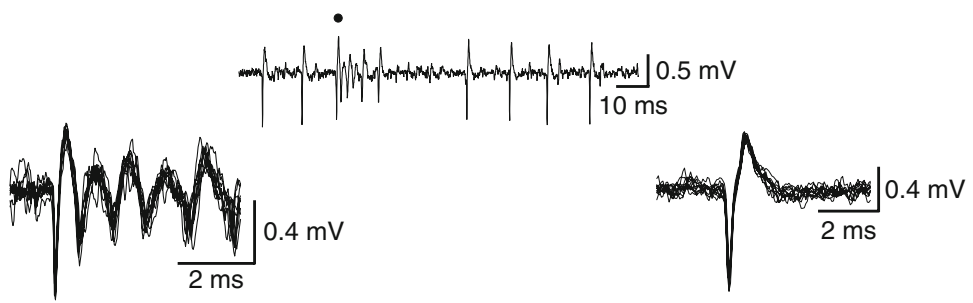

bi

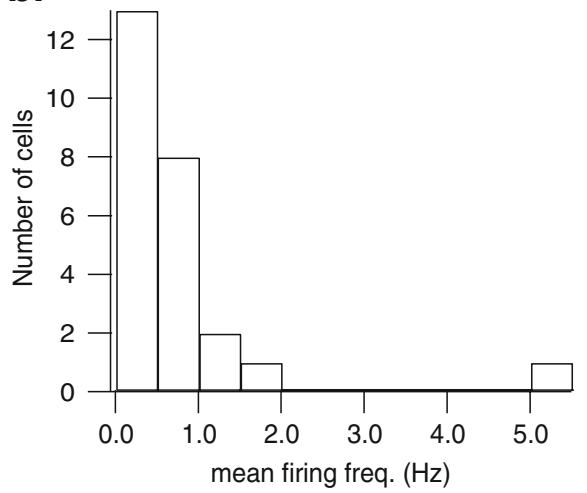

bii

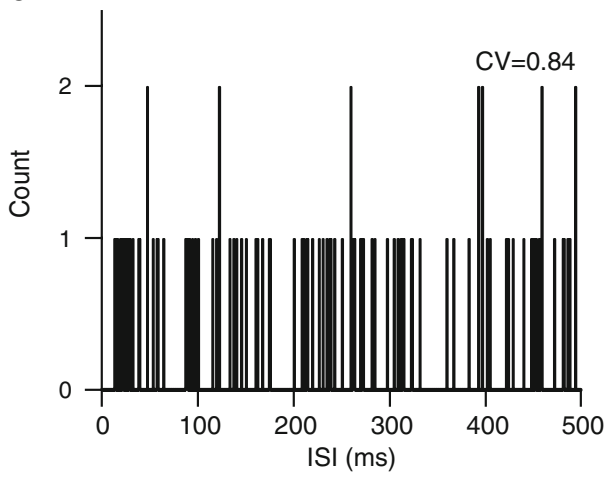

biii

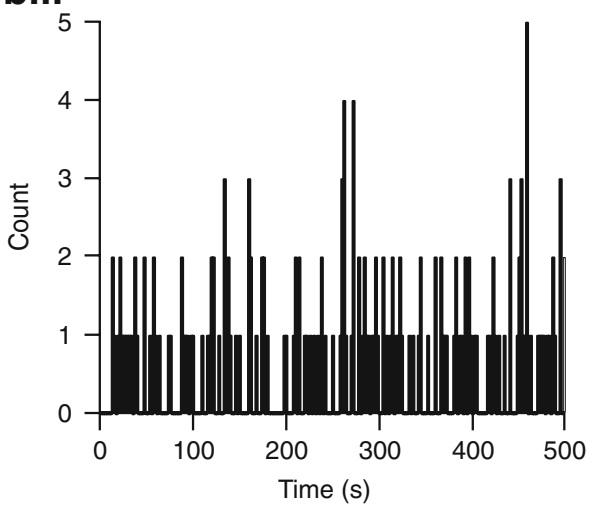

d

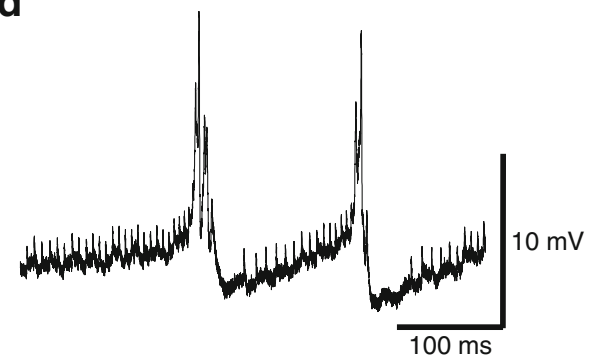

ci

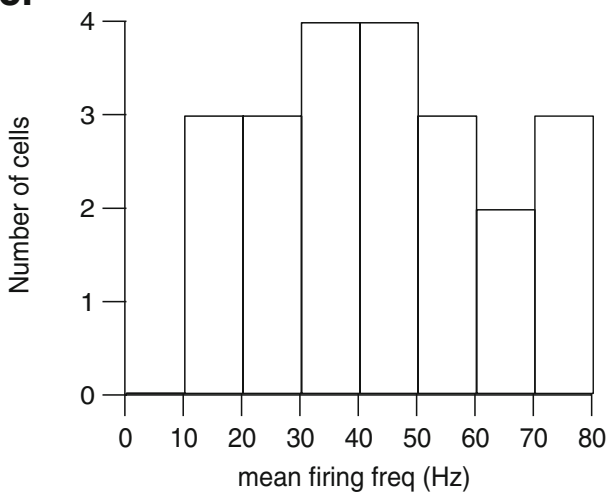

cii

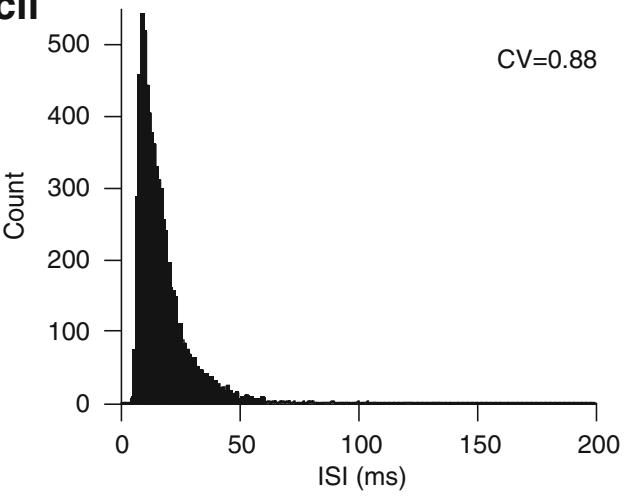

ciii

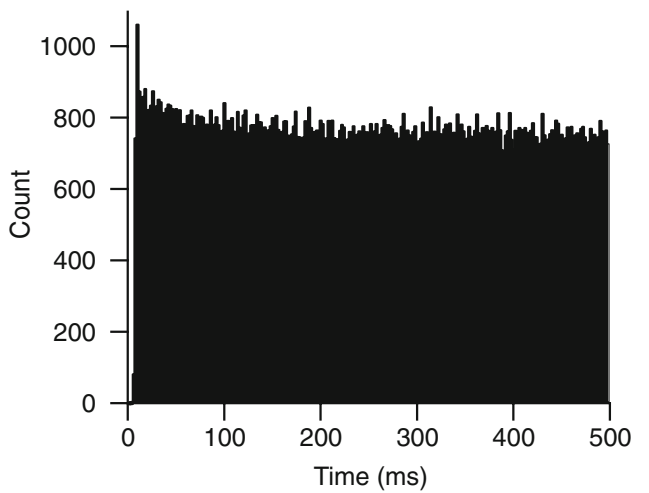


Table 1). Purkinje cells displayed a wide range of individual firing rates (11-76 Hz, Fig. $4 \mathrm{ci}$ ), with an overall mean rate of $42.6 \pm 4.2 \mathrm{~Hz}$. The irregularity of simple spike firing was also demonstrated by autocorrelograms (Fig. 4 ciii). Importantly, none of the 22 Purkinje cells studied in detail displayed the rhythmic pacemaker-like pattern of simple spike firing that occurs in the absence of normal background excitatory synaptic input $[14,17]$. Although not studied systematically, we were also able to make intracellular recordings from Purkinje cells. For example, Fig. 4d, demonstrates a recording characteristic of Purkinje cell proximal dendritic recordings $[15,48]$.

A total of 19 units were categorised as cerebellar interneurones, based on their depth in the cerebellar cortex, spike waveform, absence of complex spikes and firing patterns as determined previously in vivo $[49,50]$. Putative molecular layer interneurones $(n=13)$ were located in the superficial part of the cerebellar cortex at depths 100 $300 \mu \mathrm{m}$ below the surface including just above the Purkinje cell layer. Typically, they had biphasic positive-negative action potentials $>0.8 \mathrm{~ms}$ (Table 1; Fig. 5 ai). They fired more slowly and regularly than Purkinje cells, at rates of $1.5-27.5 \mathrm{~Hz}$ (Fig. 5 aii; mean firing rate of $12.7 \pm 2.3 \mathrm{~Hz}$ ). Their more regular rate of discharge was evident in their interspike interval histograms which tended to be more symmetrical than those of Purkinje cells (Fig. 5 aiii) and their tendency to fire rhythmically was evident by the presence of multiple peaks at regular intervals in their autocorrelograms (Fig. 5 aiv).

Putative Golgi cells $(n=6)$ were located in the granular layer of the cerebellar cortex, below the Purkinje cell layer and had long duration $(>1.1 \mathrm{~ms})$ biphasic action potentials (Fig. 5 bi), and a long tuning distance $(>100 \mu \mathrm{m}$ electrode movement). In comparison to Purkinje cells, putative Golgi cells exhibited a slower although irregular firing rate (range, 3.7-26.4 Hz; Fig. 5 bii; mean firing rate $12.0 \pm 3.3 \mathrm{~Hz}$; Table 1). The more irregular firing rate of putative Golgi cells was evident in their interspike interval histograms (Fig. 5 biii) which had broader peaks, longer intervals between spikes (Table 1) and a lack of multiple peaks in their autocorrelograms (Fig. 5 biv).

To assess whether stable recordings from cerebellar cortical neurones could be maintained in the PHBP over extended periods without any deterioration in their firing properties, four of the cerebellar neurones (three Purkinje cells and one interneurone) were recorded for a duration of 1.5-3.5 h. No significant difference was found (paired $t$ test, $P>0.05$ ) in the mean firing rate and coefficient of variation when the spike trains in the first half of the recording period were compared to those obtained in the final half.

Extracellular recordings were also made of the spontaneous activity of six units in nucleus interpositus. In each 
Fig. 5. Cerebellar cortical interneurones. ai Spontaneous activity of a molecular layer interneurone. Lower panel shows ten superimposed spikes at an expanded time base. aii Interspike interval distribution of molecular layer interneurone activity. aiii Population histogram of mean firing rates of molecular layer interneurones $(n=13)$ aiv Autocorrelogram of molecular layer interneurone spontaneous activity. bi Spontaneous activity of a putative Golgi cell. Lower panel shows ten superimposed spikes at an expanded time base. bii Interspike interval distribution of Golgi cell activity. biii Population histogram of mean firing rates of Golgi cells $(n=6)$. biv Autocorrelogram of Golgi cell spontaneous activity. $C V$ coefficient of variation ai

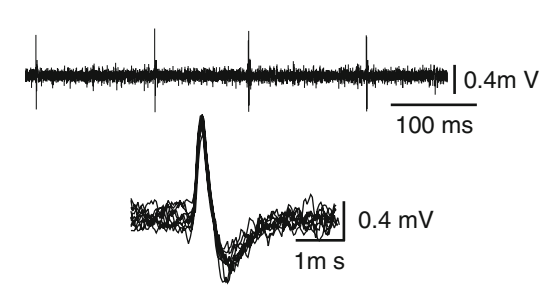

aii

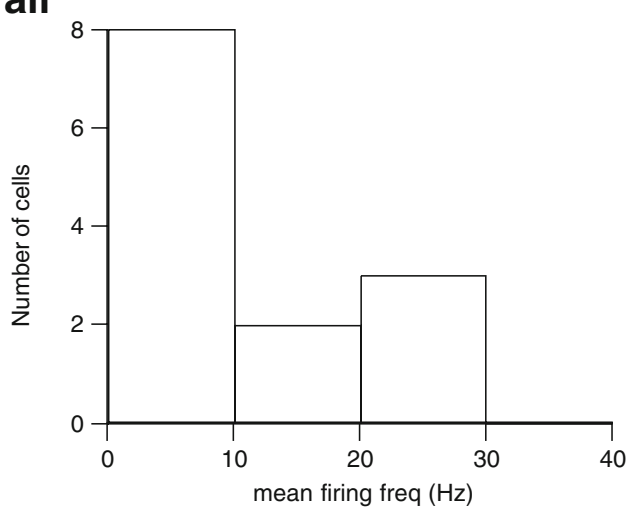

aiii

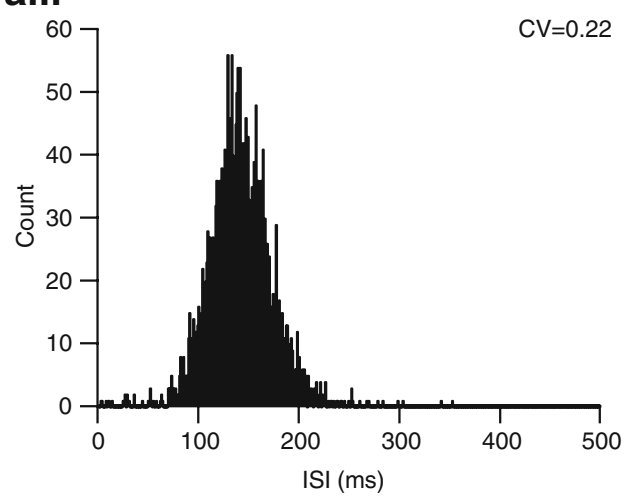

aiv

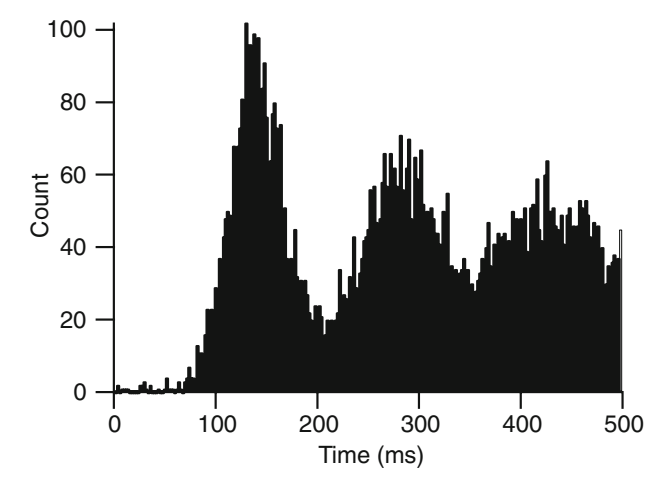

bi

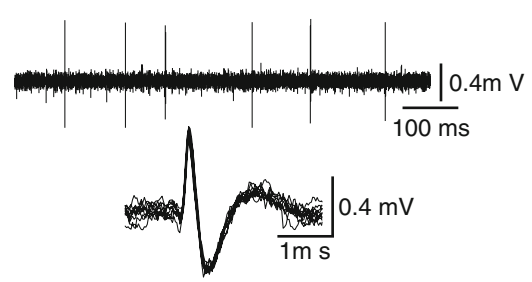

bii

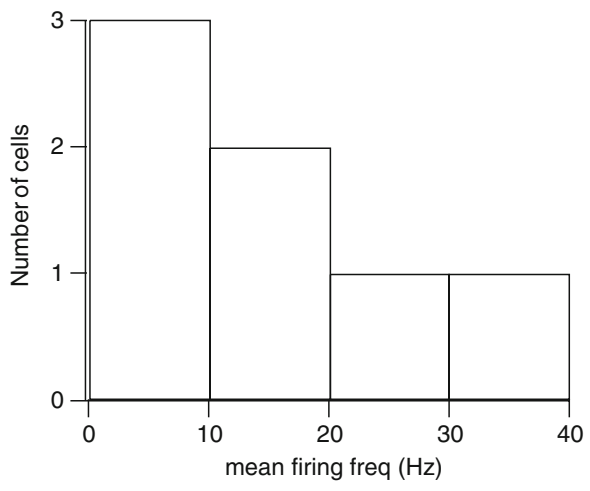

biii

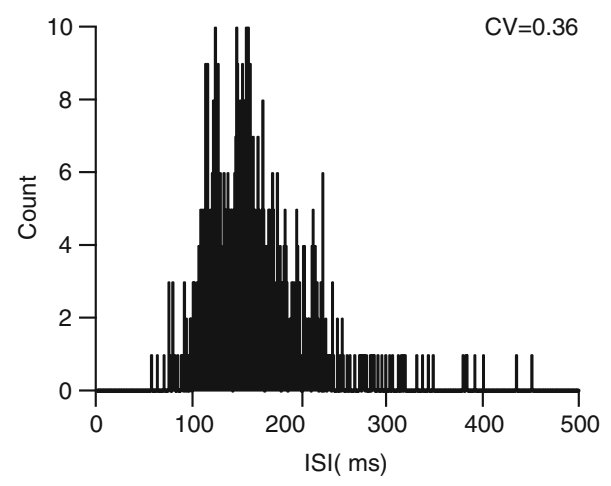

biv

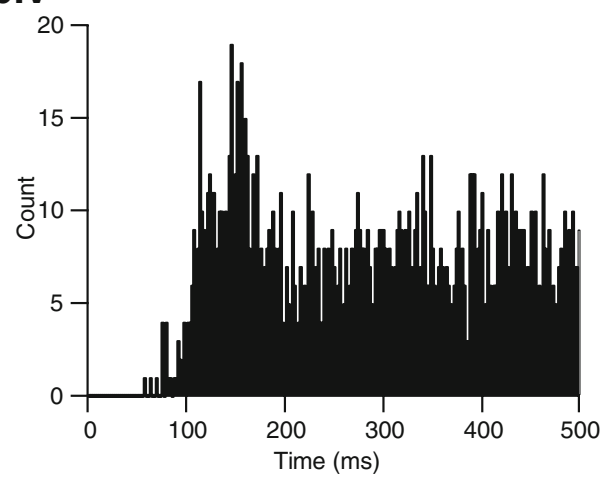

case, the spikes were mainly biphasic positive-negative action potentials with a duration $>0.8 \mathrm{~ms}$ (Fig. 6a) with mean firing rates between 13.1-49 Hz (Fig. 6b; Table 1). In general, interpositus neurones displayed a highly irregular discharge pattern (coefficient of variation ranged from 0.41-1.94; mean, 1.07 \pm 0.25 ); interspike interval histograms were positively skewed (Fig. 6c; Table 1) and no prominent peaks or troughs were evident in their autocorrelograms (Fig. 6d).

Purkinje cells and interpositus neurones were also found to be responsive to tactile stimulation and electrical stimulation of the periphery. In the example shown in Fig. 7a, light pressure of the periorbital region with a probe resulted in an increase in firing frequency above resting 
Fig. 6. Cerebellar nuclear neurones. a Spontaneous activity of a cerebellar interpositus neurone. Lower panel shows ten superimposed spikes at an expanded time base. b Interspike interval histogram of a cerebellar interpositus neurone. c Population histogram of mean firing rates of nuclear neurones $(n=6)$. d Autocorrelogram of spontaneous activity of nuclear neurone a

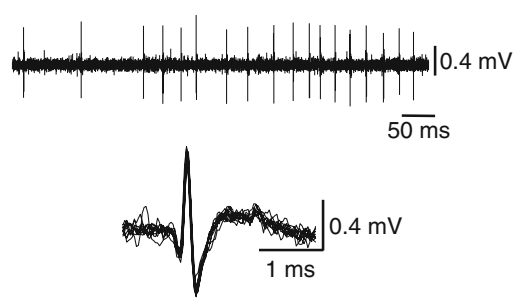

C

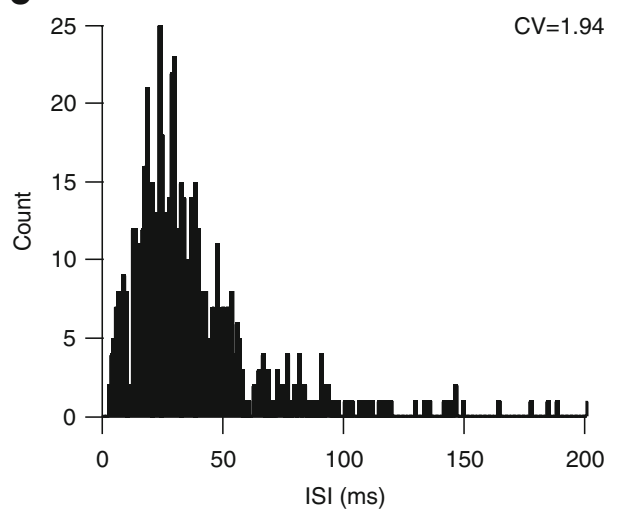

b

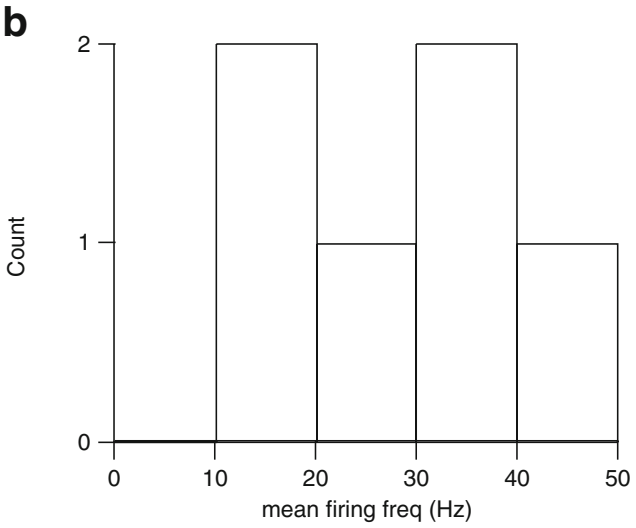

d

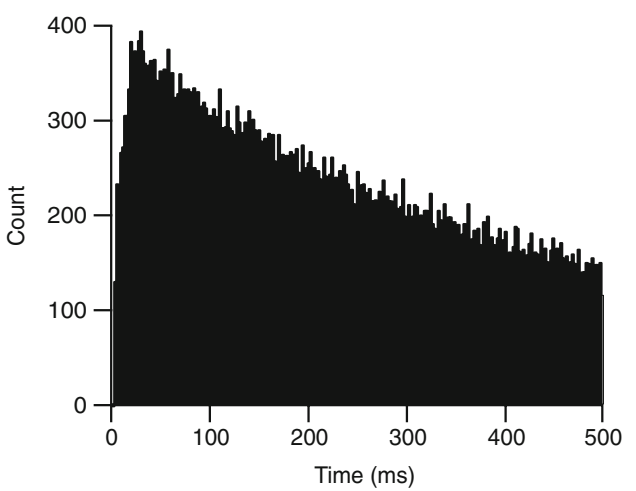

discharge rates in an interpositus neurone while Fig. $7 \mathrm{~b}$ shows that electrical stimulation of the facial nerve caused a phasic increase and subsequent phasic decrease in Purkinje cell simple spike activity. Thus, mechanical and electrical peripheral stimuli can be effective at modifying the firing patterns of cerebellar neurones in the PHBP.

Finally, in two experiments we tested the effects of adding harmaline to the perfusate. Harmaline has long been known as a tremogenic agent that acts on the inferior olive [e.g. 51, 52]. Consistent with previous studies in the intact animal, harmaline caused an increase in the frequency of complex spikes (from $\sim 0.2 \mathrm{~Hz}$ to $2.0 \mathrm{~Hz}$ ), accompanied by the development of a rhythmic pattern of firing, while simple spike activity was abolished (not shown).

\section{Discussion}

The present study investigates the use of a novel decerebrate perfused hindbrain and upper body in situ preparation that maintains the cerebellum in relation to its extrinsic connections. Although the cerebro-cerebellar pathway is absent, nevertheless some cerebellar circuits can still be maintained in the absence of this input. Field potential analysis and EMG recordings provided evidence that at least some of the major cerebellar input and output
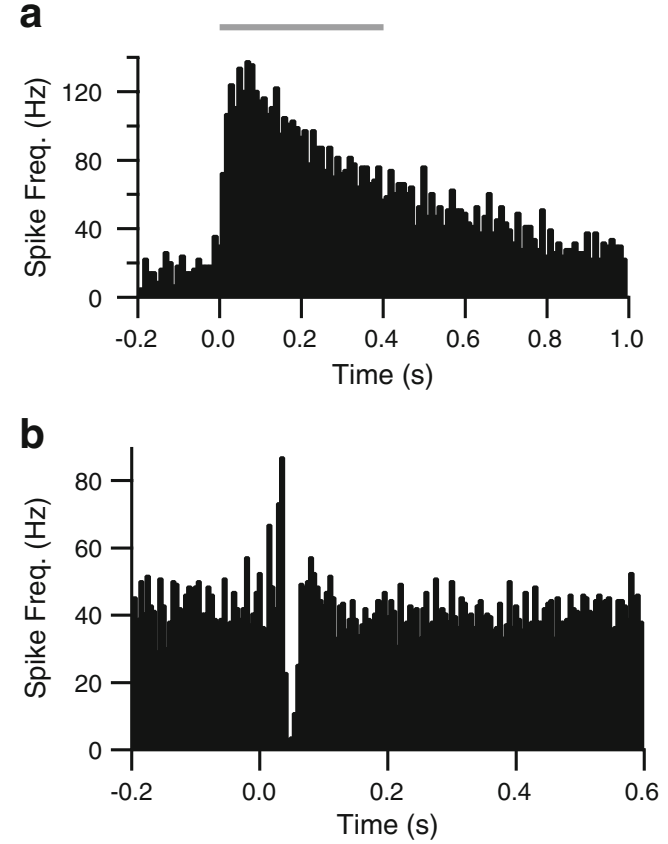

Fig. 7. Cerebellar neuronal responses to peripheral stimulation. a Peri-event time histogram of the activity of a cerebellar interpositus nuclear neurone in response to mechanical stimulation of the periorbital region. Period of mechanical stimulation is indicated by length of horizontal bar. b Peri-event time histogram of the simple spike activity of a Purkinje cell in response to electrical stimulation of the facial nerve. Stimulus onset $=$ time 0 . Bin size $=10 \mathrm{~ms}$ 
pathways remain operational in this preparation, and single cell recordings indicated that cerebellar neuronal activity was in most cases very similar to results obtained in vivo.

Comparison with Physiological Studies In vivo and In vitro

Extracellular recordings of Purkinje cell simple spike activity, putative Golgi cells and molecular layer interneurones indicated that such cells were tonically active in the PHBP. Average firing rates, spike widths, interspike intervals and coefficients of variation were all within the ranges reported by others in anaesthetised rats [53-56], as well as awake rats $[57,58]$ and cats $[59,60]$. For example, simple spike activity of Purkinje cells in anaesthetised and awake animals at rest exhibit mean firing rates of $40-50 \mathrm{~Hz}$ while the mean firing rate found in the PHBP was $\sim 45 \mathrm{~Hz}$. Likewise, molecular layer interneurones and Golgi cells exhibit mean firing rates of $10-30 \mathrm{~Hz}[56,61]$ and $2-25 \mathrm{~Hz}$, respectively $[49,50,56,60]$ which compares favourably to the mean rates found in the PHBP $(\sim 13 \mathrm{~Hz}$ for molecular layer interneurones and $\sim 11 \mathrm{~Hz}$ for putative Golgi cells).

Similarly, spontaneous firing rates of cerebellar nuclear neurones have been reported to be $34 \mathrm{~Hz}$ in the awake cat [59], while in the PHBP the corresponding value is $32 \mathrm{~Hz}$. However, this value is lower than the rate of $55 \mathrm{~Hz}$ reported in P50-100 day anaesthetised rats [54] and the rate of $43 \mathrm{~Hz}$ reported in P20-26 day awake rats [62]. The lower mean firing rate in the PHBP may be due to the lack of excitatory drive from nuclear collateral inputs arising from cerebro-ponto-cerebellar projections [e.g 63] and/or the lower temperature $\left(32-34^{\circ} \mathrm{C}\right)$ used to maintain the PHBP, as dissociated cerebellar nuclear cells maintained at $31^{\circ} \mathrm{C}$ discharge at approximately $20 \mathrm{~Hz}$ [64].

The majority $(\sim 85 \%)$ of Purkinje cells recorded in the PHBP discharged complex spikes at $<1.0 \mathrm{~Hz}$. This is consistent with studies in ketamine/xylazine anaesthetised rats [53], and awake mice [65], but is somewhat lower than reported in other in vivo preparations (e.g $1.5 \mathrm{~Hz}$, [61], $1.52 \mathrm{~Hz},[66], 1.34 \mathrm{~Hz}$, [56]). An important consideration is decerebration which may have affected complex spike firing rates. In decerebrate animals complex spikes were found to be detectable in only one third of Purkinje cells [32, 36], and lower mean complex spike firing rates have been reported in the decerebrate ferret $(0.48 \mathrm{~Hz},[67])$ and cat $(0.67 \mathrm{~Hz},[68])$. Nevertheless, it appears that when the climbing fibre system is being driven in the PHBP, as was the case in the climbing field potential mapping and in the harmaline experiments, the latency and patterns of responses closely matched those reported in intact preparations (e.g. [28, 69, 70]). The mossy fibre-parallel fibre system also appears to be normal; mossy fibre related potentials in the cerebellar cortex displayed all the features characterised in vivo [36-38] and the conduction velocities of parallel fibres were in close agreement with those obtained in vivo in the cat $[30,33]$. In contrast, parallel fibre conduction velocities obtained in adult and juvenile rat cerebellar slices are slower [34], suggesting that a more

Table 2 Advantages and disadvantages of the PHBP preparation

\section{ADVANTAGES}

Allows access to parts of rodent cerebellum not accessible in vivo (in both decerebrate and anaesthetised preparations), notably the anterior lobe.

Unlike in vitro preparations, the PHBP retains functional connectivity between the cerebellum, brainstem and the upper body and head (and can be modified to include the whole body if required)

The high mechanical stability combined with increased accessibility allows for long term recording/stimulation of multiple hindbrain sites

Avoids the complications of anaesthesia

Allows greater control over pharmacological manipulations as drugs can be rapidly introduced and washed out, and neurotoxins can be used that would be lethal in vivo

In contrast to in vitro preparations the PHBP allows the study of a range of different sensory modalities, including: cutaneous and proprioceptive pathways, and whisker sensory inputs to hindbrain circuits

The PHBP is quicker and easier to set up than in vitro preparations

DISADVANTAGES

The main limitation is that the PHBP is decerebrate. This will deprive the cerebellum of a major source of input. If required, anaesthesia can be used as an alternative to decerebration

Young age of rats (P45). However it should be noted that the animals are older than those frequently used in in vitro studies

Cerebellar anatomical landmarks are less clear as major blood vessels such as the paravermal vein are transparent. However, dye can be introduced into the perfusate to temporarily mark blood vessels

Viability is limited to about $5 \mathrm{~h}$

Peripheral electrical stimulation and recording (e.g. of nerves) is more complicated than in vivo because of the perfusate; electrical contacts need to be made water tight

The thorax and upper forelimbs are usually skinned to prevent clogging of tubing/filters with hair and debris. This will alter sensory inputs but regions of skin of interest can be left intact e.g. the face (including whiskers) and distal forelimbs 
intact preparation may be beneficial when studying the parallel fibre system.

\section{Advantages and Disadvantages of the PHBP}

Table 2 summarises the advantages and disadvantages of the PHBP. By comparison to studies in anaesthetised animals the PHBP has a number of advantages: (1) Cerebellar circuitry can be studied without the complication of anaesthetics, which are known to have a profound effect on transmission of sensory-evoked responses [37, 71]. (2) the PHBP, like previous 'block' preparations [21, 22, 2427], allows direct access to areas of the cerebellum (and brainstem) that are difficult to reach in vivo, such as rostral parts of the cerebellar anterior lobe, paraflocculus and flocculus. (3) Also by contrast to in vivo preparations, respiratory and heart movements can be eliminated if necessary, so stable recordings are possible which can be maintained for extended periods of time (in the case of extracellular recordings for several hours if necessary) with no detectable change in firing properties.

By comparison to in vitro brain slice preparations, an additional important feature of the PHBP is that it also preserves hindbrain connections with the head and forelimbs. The latter is particularly useful when examining cerebellar pathways involved in the control of forelimb movements, as nucleus interpositus projections to the cervical spinal cord and forelimb muscles appear to function as normal in this preparation. Also in contrast to slice preparations, the PHBP is relatively quick to set up; approximately $30 \mathrm{~min}$, whereas slice preparations can take up to $2 \mathrm{~h}$. However, the length of the recording period in the PHBP is highly dependent on the adequacy of perfusion and how rapidly perfusion is initiated. For this purpose, monitoring of phrenic nerve activity is essential as the neurogram is a reliable indicator of the general viability of the preparation. On occasions when phrenic activity was abnormal (tonic or apneic), little or no neuronal activity could be obtained from the cerebellum. In preparations with adequate perfusion, recordings are possible for up to $5 \mathrm{~h}$. After this time, recording quality rapidly declines in parallel with general deterioration of the preparation as determined by a change in phrenic nerve activity from regular ramp-like bursts to irregular activity.

In terms of limitations, the young age of rats (P45) used for the preparation is a potential concern. Morphological and functional maturation of rat mossy fibre-granule cell synapses occurs later (P60) [72, 73]. However, a viable preparation is critically dependent on adequate perfusion pressure. This precludes the use of adult animals due to the substantial increase in perfusion flow rate required in order to achieve sufficient perfusion of the vascular tree as well as the increased risk of hypoxic insult during preparation. Attempts to increase flow rates in larger animals by increasing the pump flow rates were unsuccessful, because phrenic nerve activity becomes abnormal (exhibits tonic activity) and the preparation rapidly becomes oedematous. Therefore for a viable preparation, younger animals need to be used in comparison to those normally used for in vivo studies. Nevertheless, the upper age limit of the animals (P35-45) is older than those used for some in vitro investigations (P11-25, e.g. [74-76]).

Other limitations of the PHBP include difficulty in identifying different cerebellar regions due to the lack of visible surface blood vessels as anatomical landmarks, and the lack of skin inputs. However, regions of skin can be left intact and the preparation can include the whole body if required. A further and arguably the most important limitation is the lack of cerebro-cerebellar projections. Although Purkinje cell simple spikes could be activated by peripheral stimulation, we were not able to record longer latency field potential responses attributed to cerebral cortical inputs, most likely due to the decerebration [7779]. Note however that decerebrate preparations can be used to study some aspects of cerebellar contributions to a range of behavioural responses such as eye blink conditioning (for e.g. [45, 80, 81]); but see [82] and motor control (for e.g. [83-85]). Also, if descending pathways are to be studied, then the preparation can be anaesthetised through the addition of anaesthetics to the perfusate whilst leaving the cerebral cortex intact [86].

In conclusion, the present study provides evidence that the cerebellum and some of its major interconnections with the rest of the nervous system remain operational in the PHBP. The PHBP should therefore be a useful complement to in vivo and in vitro models for studies requiring stable recordings of single neurones over several hours (including simultaneous recordings), whilst retaining interconnections with other neuronal networks, such as those involved in the control of forelimb movements.

Acknowledgements The help and advice of Professor Julian Paton, Dr. Ana-Paula Abdala and Dr. Vagner Atunes are gratefully acknowledged.

Grants This work was supported by the Wellcome Trust, BBSRC, and a Benjamin Meaker Visiting Professorship.

Open Access This article is distributed under the terms of the Creative Commons Attribution Noncommercial License which permits any noncommercial use, distribution, and reproduction in any medium, provided the original author(s) and source are credited.

\section{References}

1. Potts JT, Spyer KM, Paton JF (2000) Somatosympathetic reflex in a working heart-brainstem preparation of the rat. Brain Res Bull 53(1):59-67 
2. Schmahmann JD (1997) International Review of Neurobiology. Academic Press, San Diego

3. Strick PL, Dum RP, Fiez JA (2009) Cerebellum and nonmotor function. Ann Rev Neurosci 32:413-434

4. Ito M (1984) The Cerebellum and Neural Control. Raven Press, New York

5. Apps R, Garwicz M (2005) Anatomical and physiological foundations of cerebellar information processing. Nat Rev Neurosci 6(4):297-311

6. Bower JM, Woolston DC (1983) Congruence of spatial organization of tactile projections to granule cell and Purkinje cell layers of cerebellar hemispheres of the albino rat: vertical organization of cerebellar cortex. J Neurophysiol 49(3):745-766

7. Chadderton P, Margrie TW, Häusser M (2004) Integration of quanta in cerebellar granule cells during sensory processing. Nature 428(6985):856-860

8. Marple-Horvat DE, Stein JF (1990) Neuronal activity in the lateral cerebellum of trained monkeys, related to visual stimuli or to eye movements. J Physiol 428:595-614

9. Thach WT (1978) Correlation of neural discharge with pattern and force of muscular activity, joint position, and direction of intended next movement in motor cortex and cerebellum. J Neurophysiol 41(3):654-676

10. Brodal A, Kawamura K (1980) Olivocerebellar projection: a review. Adv Anat Embryol Cell Biol 64:1-140

11. Brodal P, Bjaalie JG (1997) Salient anatomic features of the cortico-ponto-cerebellar pathway. Prog Brain Res 114:227-249

12. Keifer J, Houk JC (1994) Motor function of the cerebellorubrospinal system. Physiol Rev 74(3):509-542

13. Aizenman CD, Huang EJ, Linden DJ (2003) Morphological correlates of intrinsic electrical excitability in neurons of the deep cerebellar nuclei. J Neurophysiol 89(4):1738-1747

14. Häusser M, Clark BA (1997) Tonic synaptic inhibition modulates neuronal output pattern and spatiotemporal synaptic integration. Neuron 19(3):665-678

15. Llinás R, Sugimori M (1980) Electrophysiological properties of in vitro Purkinje cell dendrites in mammalian cerebellar slices. J Physiol 305:197-213

16. Llinás R, Sugimori M (1980) Electrophysiological properties of in vitro Purkinje cell somata in mammalian cerebellar slices. J Physiol 305:171-195

17. Cerminara NL, Rawson JA (2004) Evidence that climbing fibers control an intrinsic spike generator in cerebellar Purkinje cells. J Neurosci 24(19):4510-4517

18. Llinás R, Walton K, Hillman DE, Sotelo C (1975) Inferior olive: its role in motor learing. Science 190(4220):1230-1231

19. Montarolo PG, Raschi F, Strata P (1980) On the origin of the climbing fibres of the cerebellar cortex. Pflugers Arch 383 (2):137-142

20. Paton JF (1996) A working heart-brainstem preparation of the mouse. J Neurosci Methods 65(1):63-68

21. Arata A, Ito M (2004) Synaptic transmission and long-term depression in Purkinje cells in an in vitro block preparation of the cerebellum isolated from neonatal rats. Prog Brain Res 148:111-123

22. Ariel M (2005) Latencies of climbing fiber inputs to turtle cerebellar cortex. J Neurophysiol 93(2):1042-1054

23. Cohen D, Yarom Y (1999) Optical measurements of synchronized activity in isolated mammalian cerebellum. Neuroscience 94 (3):859-866

24. Keifer J, Houk JC (1989) An in vitro preparation for studying motor pattern generation in the cerebellorubrospinal circuit of the turtle. Neurosci Lett 97(1-2):123-128

25. Llinás R, Muhlethaler M (1988) An electrophysiological study of the in vitro, perfused brain stem-cerebellum of adult guinea-pig. J Physiol 404:215-240
26. Llinás R, Muhlethaler M (1988) Electrophysiology of guinea-pig cerebellar nuclear cells in the in vitro brain stem-cerebellar preparation. J Physiol 404:241-258

27. Llinás R, Yarom Y, Sugimori M (1981) Isolated mammalian brain in vitro: new technique for analysis of electrical activity of neuronal circuit function. Fed Proc 40(8):2240-2245

28. Atkins MJ, Apps R (1997) Somatotopical organisation within the climbing fibre projection to the paramedian lobule and copula pyramidis of the rat cerebellum. J Comp Neurol 389(2):249-263

29. Goldberg JM, Fernandez C (1971) Physiology of peripheral neurons innervating semicircular canals of the squirrel monkey. III. Variations among units in their discharge properties. J Neurophysiol 34(4):676-684

30. Eccles JC, Llinás R, Sasaki K (1966) Parallel fibre stimulation and the responses induced thereby in the Purkinje cells of the cerebellum. Exp Brain Res 1(1):17-39

31. Chen G, Hanson CL, Ebner TJ (1998) Optical responses evoked by cerebellar surface stimulation in vivo using neutral red. Neuroscience 84(3):645-668

32. Eccles JC, Ito M, Szentágothai J (1967) The Cerebellum as a Neuronal Machine. Springer-Verlag, New York

33. Dow RS (1949) Action potentials of cerebellar cortex in response to local electrical stimulation. J Neurophysiol 12:245-256

34. Vranesic I, Iijima T, Ichikawa M, Matsumoto G, Knöpfel T (1994) Signal transmission in the parallel fiber-Purkinje cell system visualized by high-resolution imaging. PNAS 91(26):13014-13017

35. Rawson JA, Tilokskulchai K (1982) Climbing fibre modification of cerebellar Purkinje cell responses to parallel fibre inputs. Brain Res 237(2):492-497

36. Armstrong DM, Drew T (1980) Responses in the posterior lobe of the rat cerebellum to electrical stimulation of cutaneous afferents to the snout. J Physiol 309:357-374

37. Bengtsson F, Jörntell H (2007) Ketamine and xylazine depress sensory-evoked parallel fiber and climbing fiber responses. J Neurophysiol 98(3):1697-1705

38. Eccles JC, Sasaki K, Strata P (1967) Interpretation of the potential fields generated in the cerebellar cortex by a mossy fibre volley. Exp Brain Res 3(1):58-80

39. Apps R, Lee S (1999) Gating of transmission in climbing fibre paths to cerebellar cortical $\mathrm{C} 1$ and $\mathrm{C} 3$ zones in the rostral paramedian lobule during locomotion in the cat. J Physiol 516:875-883

40. Ekerot CF, Larson B, Oscarsson O (1979) Information carried by the spinocerebellar paths. Prog Brain Res 50:79-90

41. Garwicz M (1997) Sagittal zonal organization of climbing fibre input to the cerebellar anterior lobe of the ferret. Exp Brain Res 117(3):389-398

42. Armstrong DM, Harvey RJ (1968) Responses to a spino-olivocerebellar pathway in the cat. J Physiol 194(1):147-168

43. Eccles JC, Provini L, Strata P, Taborikova H (1968) Analysis of electrical potentials evoked in the cerebellar anterior lobe by stimulation of hindlimb and forelimb nerves. Exp Brain Res 6 (3):171-194

44. Ekerot CF, Jörntell H, Garwicz M (1995) Functional relation between corticonuclear input and movements evoked on microstimulation in cerebellar nucleus interpositus anterior in the cat. Exp Brain Res 106(3):365-376

45. Hesslow G (1994) Correspondence between climbing fibre input and motor output in eyeblink-related areas in cat cerebellar cortex. J Physiol 476(2):229-244

46. Giuffrida R, Li Volsi G, Panto MR, Perciavalle V, Sapienza S, Urbano A (1980) Single muscle organization of interposito-rubral projections. Exp Brain Res 39(3):261-267

47. Crépel F, Jaillard D (1991) Pairing of pre- and postsynaptic activities in cerebellar Purkinje cells induces long-term changes in synaptic efficacy in vitro. J Physiol 432:123-141 
48. Hounsgaard J, Midtgaard J (1988) Intrinsic determinants of firing pattern in Purkinje cells of the turtle cerebellum in vitro. J Physiol 402:731-749

49. Holtzman T, Rajapaksa T, Mostofi A, Edgley SA (2006) Different responses of rat cerebellar Purkinje cells and Golgi cells evoked by widespread convergent sensory inputs. J Physiol 574(Pt 2):491-507

50. Simpson JI, Hulscher HC, Sabel-Goedknegt E, Ruigrok TJ (2005) Between in and out: linking morphology and physiology of cerebellar cortical interneurons. Prog Brain Res 148:329-340

51. de Montigny C, Lamarre Y (1973) Rhythmic activity induced by harmaline in the olivo-cerebello-bulbar system of the cat. Brain Res 53(1):81-95

52. Llinás R, Volkind RA (1973) The olivo-cerebellar system: functional properties as revealed by harmaline-induced tremor. Exp Brain Res 18(1):69-87

53. Brown IE, Bower JM (2001) Congruence of mossy fiber and climbing fiber tactile projections in the lateral hemispheres of the rat cerebellum. J Comp Neurol 429(1):59-70

54. Rowland NC, Jaeger D (2005) Coding of tactile response properties in the rat deep cerebellar nuclei. J Neurophysiol 94 (2):1236-1251

55. Shin SL, Rotter S, Aertsen A, De Schutter E (2007) Stochastic description of complex and simple spike firing in cerebellar Purkinje cells. Eur J Neurosci 25(3):785-794

56. Vos BP, Volny-Luraghi A, De Schutter E (1999) Cerebellar Golgi cells in the rat: receptive fields and timing of responses to facial stimulation. Eur J Neurosci 11(8):2621-2634

57. de Solages C, Szapiro G, Brunel N, Hakim V, Isope P, Buisseret $P$ et al (2008) High-frequency organization and synchrony of activity in the Purkinje cell layer of the cerebellum. Neuron 58 (5):775-788

58. LeDoux MS, Lorden JF (2002) Abnormal spontaneous and harmaline-stimulated Purkinje cell activity in the awake genetically dystonic rat. Exp Brain Res 145(4):457-467

59. Armstrong DM, Rawson JA (1979) Responses of neurones in nucleus interpositus of the cerebellum to cutaneous nerve volleys in the awake cat. J Physiol 289:403-423

60. Edgley SA, Lidierth M (1987) The discharges of cerebellar Golgi cells during locomotion in the cat. J Physiol 392:315-332

61. Armstrong DM, Rawson JA (1979) Activity patterns of cerebellar cortical neurones and climbing fibre afferents in the awake cat. J Physiol 289:425-448

62. LeDoux MS, Hurst DC, Lorden JF (1998) Single-unit activity of cerebellar nuclear cells in the awake genetically dystonic rat. Neuroscience 86(2):533-545

63. Shinoda Y, Sugiuchi Y, Futami T (1987) Excitatory inputs to cerebellar dentate nucleus neurons from the cerebral cortex in the cat. Exp Brain Res 67(2):299-315

64. Raman IM, Gustafson AE, Padgett D (2000) Ionic currents and spontaneous firing in neurons isolated from the cerebellar nuclei. $\mathrm{J}$ Neurosci 20(24):9004-9016

65. Goossens HH, Hoebeek FE, Van Alphen AM, Van Der Steen J, Stahl JS, De Zeeuw CI et al (2004) Simple spike and complex spike activity of floccular Purkinje cells during the optokinetic reflex in mice lacking cerebellar long-term depression. Eur $\mathbf{J}$ Neurosci 19(3):687-697

66. Lang EJ, Sugihara I, Welsh JP, Llinás R (1999) Patterns of spontaneous Purkinje cell complex spike activity in the awake rat. J Neurosci 19(7):2728-2739

67. Bengtsson F, Svensson P, Hesslow G (2004) Feedback control of Purkinje cell activity by the cerebello-olivary pathway. Eur J Neurosci 20(11):2999-3005
68. Sato Y, Miura A, Fushiki H, Kawasaki T (1992) Short-term modulation of cerebellar Purkinje cell activity after spontaneous climbing fiber input. J Neurophysiol 68(6):2051-2062

69. Stratton SE, Lorden JF, Mays LE, Oltmans GA (1988) Spontaneous and harmaline-stimulated Purkinje cell activity in rats with a genetic movement disorder. J Neurosci 8 (9):3327-3336

70. Yamamoto T, Fukuda M, Llinás R (2001) Bilaterally synchronous complex spike Purkinje cell activity in the mammalian cerebellum. Eur J Neurosci 13(2):327-339

71. Gordon M, Rubia FJ, Strata P (1973) The effect of pentothal on the activity evoked in the cerebellar cortex. Exp Brain Res 17(1):50-62

72. Hámori J, Somogyi J (1983) Differentiation of cerebellar mossy fiber synapses in the rat: a quantitative electron microscope study. J Comp Neurol 220(4):365-377

73. Wall MJ, Usowicz MM (1998) Development of the quantal properties of evoked and spontaneous synaptic currents at a brain synapse. Nat Neurosci 1(8):675-682

74. Aizenman CD, Linden DJ (1999) Regulation of the rebound depolarization and spontaneous firing patterns of deep nuclear neurons in slices of rat cerebellum. Journal of Neurophysiology 82(4):1697-1709

75. Forti L, Pouzat C, Llano I (2000) Action potential-evoked Ca2+ signals and calcium channels in axons of developing rat cerebellar interneurones. J Physiol 527(Pt 1):33-48

76. Williams SR, Christensen SR, Stuart GJ, Häusser M (2002) Membrane potential bistability is controlled by the hyperpolarization-activated current $\mathrm{I}(\mathrm{H})$ in rat cerebellar Purkinje neurons in vitro. J Physiol 539(Pt 2):469-483

77. Lu H, Hartmann MJ, Bower JM (2005) Correlations between Purkinje cell single-unit activity and simultaneously recorded field potentials in the immediately underlying granule cell layer. J Neurophysiol 94(3):1849-1860

78. Morissette J, Bower JM (1996) Contribution of somatosensory cortex to responses in the rat cerebellar granule cell layer following peripheral tactile stimulation. Exp Brain Res 109(2):240-250

79. Roggeri L, Rivieccio B, Rossi P, D'Angelo E (2008) Tactile stimulation evokes long-term synaptic plasticity in the granular layer of cerebellum. J Neurosci 28(25):6354-6359

80. Ivarsson M, Svensson P (2000) Conditioned eyeblink response consists of two distinct components. J Neurophysiol 83 (2):796-807

81. Jirenhed DA, Bengtsson F, Hesslow G (2007) Acquisition, extinction, and reacquisition of a cerebellar cortical memory trace. J Neurosci 27(10):2493-2502

82. Sanchez-Campusano R, Gruart A, Delgado-Garcia JM (2009) Dynamic associations in the cerebellar-motoneuron network during motor learning. J Neurosci 29(34):10750-10763

83. Lou JS, Bloedel JR (1992) Responses of sagittally aligned Purkinje cells during perturbed locomotion: synchronous activation of climbing fiber inputs. J Neurophysiol 68(2):570 580

84. Schwartz AB, Ebner TJ, Bloedel JR (1987) Responses of interposed and dentate neurons to perturbations of the locomotor cycle. Exp Brain Res 67(2):323-338

85. Udo M, Matsukawa K, Kamei H, Minoda K, Oda Y (1981) Simple and complex spike activities of Purkinje cells during locomotion in the cerebellar vermal zones of decerebrate cats. Exp Brain Res 41(3-4):292-300

86. St-John WM, Rudkin AH, Homes GL, Leiter JC (2006) Changes in respiratory-modulated neural activities, consistent with obstructive and central apnea, during fictive seizures in an in situ anaesthetized rat preparation. Epilepsy Res 70(2-3):218-228 